\title{
Editorial
}

\section{Torture and philosophy}

Regular readers of the fournal may raise an eyebrow at the publication in this issue of a discussion by two philosophers of whether there can be ethical grounds for opposing torture. Many people will naturally feel that such a question is not worth discussing, especially in a journal devoted to medical ethics. After all, the first clause of the Declaration of Tokyo (adopted by the World Medical Association in 1975) states unequivocably:

The doctor shall not countenance, condone or participate in the practice of torture or other forms of cruel, inhuman or degrading procedures, whatever the offence of which the victim of such procedures is suspected, accused or guilty, and whatever the victim's beliefs, or motives, and in all situations including armed conflict and civil strife.

Why then bother with a theoretical discussion of the permissibility of torture? To answer this we must realise that the philosopher's concern is with theoretical justifications which can be provided for our intuitive moral repugnance at actions like the use of torture (a repugnance not shared by everyone in past generations or indeed by all of our own contemporaries, apparently). In particular, Gary Jones wants to discover whether an ethics based on Utilitarianism (the greatest happiness or greatest benefit of the majority) can provide convincing arguments against the use of torture. He concludes that it cannot, a view endorsed in the accompanying commentary by Paul Brownsey who goes on to suggest what philosophical and theological principles would be required to make such a case.

One can be sure that the statements by Jones and Brownsey will not be the last words on the issue from the side of philosophy. The relative merits of Utilitarianism and rival ethical theories for doing justice to our ordinary moral intuitions will continue to be debated in a discipline which thrives on the interplay of thesis and counterthesis. But, is such a debate of any practical value to medical ethics? Our answer must be both, Yes and No. On the positive side, we should always welcome the struggle to find rational justification for moral values. At the very least, such an exercise can help us to clarify our own fundamental moral commitments. (For example, do we favour individual rights above communal benefit, or the opposite ?). We may even hope that the humanitarian values on which medicine claims to be based may gain a wider acceptance when rationally debated and defended.

On the negative side, however, we must note the limitations of a purely philosophical approach to this aspect of medical ethics. For the philosopher, ensuring purity of argument is all important rightly so, for that is his skill and his vocation. But some medical practitioners must make quite definite decisions about participation in interrogation, sometimes under duress from civil or military authorities, sometimes under subtler social and psychological pressure. To help them, we need to complement the philosophical analysis with the warnings and recommendations of people who face the issues in practice. Therefore in a future issue we shall publish a group of practically orientated articles under the topic heading: 'Doctors and Torture'. Meanwhile, we invite the views of our readers on the features of the debate published in this issue.

\section{Discussion resuscitated}

Quarterly publication has its limitations. One can hardly be topical in the sense that the daily or weekly press is (or purports to be). However, the main themes of medical ethics recur in the news with remarkable regularity, and it is perhaps a depressing fact that the terms in which they are discussed alter very little over time. A more serious problem with our frequency of publication is continuity. It is hard for readers to recall the details of an article after a lapse of three months or more. Yet it is our intention to sustain a dialogue between contributors through successive issues using our Debate section. (In this issue, two authors, Jack Arbuthnot and Ian Kennedy, continue the dialogue with their respective commentators). We have adopted this practice on the assumption that the fournal is widely used as a work of reference and collected as such. Thus, while we cannot claim to be sustaining a live discussion over such a wide time interval, we hope that we are providing the necessary means and incentive for resuscitation of some of the more contentious issues. 